patent at later re-examination. G. C. Morris and colleagues' experience was similar but with fewer late occlusions. ${ }^{12}$

The effect of successful bypass grafting on left ventricular performance has been studied. ${ }^{18} 19$ While the temporary depression of contractile force which is associated with angina is relieved, left ventricular dysfunction unassociated with pain is not improved. ${ }^{19}$ This is hardly surprising. Moreover, the operative mortality of surgery in patients with generalized depression of left ventricular contraction is high and the chances of benefit are poor. Such patients tend to have coronary vessels which are the seat of diffuse occlusive disease and so unsuitable for grafting, and the fibrous replacement in their myocardium is in any case irreversible.

Until more is known of the long-term fate of the grafts the indications for operation should probably be restricted to the relief of angina and not extended to the possible prophylaxis of future infarction in patients without severe symptoms. Emergency bypass grafting probably has a place in impending infarction. Even after infarction it is possible that the zone of necrosis can be minimized and borderline ischaemic territory reclaimed by this means in some instances. In cases of unstable or crescendo angina refractory to conventional management, investigation and operation may also be indicated, but the prognosis of unstable angina treated medically is relatively good for life, and the justification for surgical operation remains to be proved.

Though recent surgical experience is encouraging, ${ }^{13} \mathrm{M}$. Fulton and colleagues ${ }^{20}$ in Edinburgh found that only 3 out of 167 patients with unstable angina died suddenly, a medical outcome which would be hard to beat by surgical means. Only $23(14 \%)$ of these same patients went on to myocardial infarction. It is interesting that $60 \%$ of 110 patients with myocardial infarction had had preceding unstable angina but only a quarter of them had actually reported this symptom to their doctors. Thus while unstable angina is the best predictor of myocardial infarction this is not true for sudden death. It seems that a case cannot yet be made for coronary artery bypass to prevent infarction in patients with unstable angina, except perhaps where a main stem stenosis of the left coronary artery is found.

The position of the operation in the treatment that may be offered a patient is still uncertain. ${ }^{21} 22$ Though it has real value, the low mortality and excellent objective as well as symptomatic benefit reported from a few large centres cannot quickly be reproduced in units which are just starting up. Coronary angiography alone can carry a greater hazard in the hands of the novice than investigation and operation together when performed by experts. Successful surgery depends on skilled interpretation of high-definition angiograms, correct choice of patients, and a surgical technique which is more demanding than that required for the insertion of prosthetic valves. The Cleveland operation rightly achieved instant acclaim, but now its growing application threatens to dominate cardiac surgery and to menace the organization of cardiothoracic services. Excessive enthusiasm has so far been avoided in Britain. Restraint is still needed until the indications for this operation have been clarified by controlled trial and until the special skills and facilities are available to carry it out if the trial shows it to be a real advance.

\footnotetext{
1 Campbell, M., British Medical Fournal, 1963, 2, 712.

2 Grace, W. J., and Keyloun, V., The Coronary Care Unit, p. 76. London, Butterworths, 1970.

3 Effler, D. B., Favaloro, R. G., Groves, L. K., and Loop, F. D., Fournal of Thoracic and Cardiovascular Surgerv, 1971, 62, 503.

1 Vineberg, A. M., Canadian Medical Association fournal, 1946, 55, 117.
}

${ }^{5}$ Fergusson, D. J., Shirey, E. K., Sheldon, W. C., Effler, D. B., and Sones, F. M., jun., Circulation, 1968, 37/38, Supplement 2, 24

- Sones, F. M., jun., and Shirey, E. K., Modern Concepts of Cardiovascular Diseases, $1962,31,735$.

7 Effler, D. B., Groves, L. K., Sones, F. M., jun., and Shirey, E. K.,

Fournal of Thoracic and Cardiovascular Surgery, $1964,47,98$.
8 Effler, D. B., Groves, L. K., Suarez, E. L., and Favaloro, R. G., Fournato Effler, D. B., Groves, L. K., Suarez, E. L.,, and Favalo

- Favaloro, R. G., Effler, D. B., Groves, L. K., Sones, F. M., jun., and Fergusson, D. J. G., fournal of Thoracic and Cardiovascular Surgery $1967,54,359$.

10 Johnson, W. D., Flemma, R. J., and Lepley, D., jun., Annals of Thoracic. Surgery, 1970, 9, 436

1 Favaloro, R. G., Effler, D. B., Groves, L. K., Sheldon, W. C., and Sones F. M., Annals of Thoracic Surgery, 1970, 10, 97.

12 Morris, G. C., et al., American fournal of Cardiology, 1972, 29, 180.

13 Flemma, R. J., et al., 21 st Annual Meeting of the American College of Cardiology, Chicago March 1972.

14 Flemma, R. J., Johnson, W. D., and Lepley, D., jun., Archives of Surgery $1971,103,82$.

15 Grondin, C. M., Lepage, G., Castonguay, Y. R., Meere, C., and Grondong P., Circulation, 1971, 44, 815 .

${ }^{16}$ Aldridge, H. E., and Trimble, A. S., Fournal of Thoracic and Cardiovascular Surgery, 1971, 62, 7

${ }^{17}$ Hallin, R. W., Page, U. S., Bigelow, J. C., and Sweetman, W. R., American fournal of Surgery, 1971, 122, 164.

18 Johnson, W. D., Flemma, R. J., Manley, J. C., and Lepley, D., fournal of Thoracic and Cardiovascular Surgery, $1970,60,483$.

10 Spencer, F. C., et al., Fournal of Thoracic and Cardiovascular Surgery $1971,62,529$.

20 Fulton, M., Duncan, B., Lutz, W., Morrison, S. L., Donald, K. W. i Kerr, F., Kirby, B. J., Julian, D. G., and Oliver, M. F., Lancet, 2. 1,860

21
22
Selzer, A., and Kerth, W. J., American fournal of Cardiology, 1971, 28, 490.

\section{Exotic Holidays and Malaria}

For many years B. G. Maegraith ${ }^{1}$ and other specialists of tropical medicine have warned us to look out for diseaseso contracted overseas and brought into Britain, for the con-ड sequences of misdiagnosis or improper treatment can be serious. $^{2}$ The recent annual report of the Public Healtho Laboratory Service ${ }^{3}$ emphasizes that the situation described by $\mathrm{P}$. Dorolle $\mathrm{D}^{4}$ has now evolved to the point when the formero International Sanitary Regulations, framed for a pre-jet age, had to be radically amended. 5 The responsibility for re cognizing imported diseases has passed from the port health officials and medical officers of health to the general practi-s tioners. It is also the general practitioner who is expected to advise the prospective traveller on how to avoid communi-3. cable diseases common in the tropics and how to suspecti their presence in anyone exposed to them. Much guidancemay be derived from two easily accessible sources. ${ }^{67}$ Someo advice is also offered in a paper by Dr. H. K. Rowland inn the B.M.F. this week (page 639).

Among various diseases that may be brought in, ranging음 from alastrim to yellow fever, malaria is undoubtedly the most imported infection, though amoebic dysentery mayN dispute the first place. In spite of the great advances made ${ }_{\sigma}^{\omega}$ by several malaria eradication programmes in subtropical and some tropical countries, the disease is still prevalent in many parts of the Middle East, in parts of the Indian sub- $-?$ continent, in most of south east Asia, and in the west Pacific. 0 In Central and South America and in practically the whole of tropical Africa endemic malaria covers huge areas.

As the holiday places have now extended from the Mediterranean to tropical Africa, Asia, and South America,, importation of malaria into the United Kingdom has be- 8 come increasingly frequent. ${ }^{8}$ The annual number of 200 cases in 1970 is probably an understatement, as notification of malaria is far from perfect. At least 2,000 cases of malaria ${ }^{+}$ were notified in this country between 1954 and 1969, but the fatality rate in 50 cases of falciparum malaria seen during this period was $10 \%$, a truly appalling figure, which indicates 
that the dangers of delayed diagnosis and treatment of this infection are not fully appreciated.

A delay in diagnosing falciparum malaria is not uncommon because the early stages of the infection may mimic many trivial diseases. Thus malaria must be suspected in any patient with fever of unknown or doubtful origin who has ever been to a subtropical or tropical area. Information on the patient's history is of paramount importance in this respeot- "Where have you been and when?" The diagnosis of malaria can be clinched by a laboratory report on a blood film, but it also requires sound clinical judgement. An outline of the main aspects of the epidemiology, prevention, diagnosis, and therapy of malaria has been given in this journal, ${ }^{9}$ and a comprehensive and handy publication of the Ross Institute of Tropical Hygiene provides much sound advice on the subject. ${ }^{10}$

Any person wishing to travel to a malarious country may be protected by a preventive drug regimen. Normally he should take prophylactic (proguanil or pyrimethamine) or suppressive drugs (chloroquine or amodiaquine). The difference between the two groups lies in their action on some specific stages of malaria parasites, but Dr. Rowland gives reasons for preferring proguanil or pyrimethamine to the suppressive drugs. These drugs should be taken at the appropriate dosage and frequency during the exposure to the infection and for four weeks after return to the nonmalarious area. Other methods of individual protection from mosquito bites, such as long sleeves and trousers after dark and a mosquito bed-net, if necessary, must not be neglected.

In some parts of the world malaria parasites have developed various degrees of resistance to common antimalarials. Resistance to proguanil and pyrimethamine may result in occasional "breakthroughs" of malaria against their prophylactic action. Moreover, during the past few years observations of resistance of $P$. falciparum to 4-aminoquinolines (chloroquine and amodiaquine) have been confirmed in Burma, Cambodia, Laos, Malaysia, Phillippines, Vietnam, parts of Brazil, Colombia, and eleswhere. It seems that this resistance is slowly spreading in eastern Asia, but there is no evidence of chloroquine resistance in Africa. Resistance to 4-aminoquinolines is causing great concern as these compounds (together with quinine) are our most valuable drugs for the treatment of acute malaria. The discovery of the potentiation between sulphones or sulphonamides on the one hand and pyrimethamine or trimethoprim on the other has given us some new and valuable drug combinations for treatment of malaria resistant to other synthetic compounds. ${ }^{11}$ Lately two antibiotics (lincomycin and tetracycline) have shown some promise. Much research on chemotherapy of malaria is in progress, particularly in the U.S.A., and it is likely that some new antimalarials will emerge from the large number of compounds now undergoing laboratory tests and field trials.

1 Maegraith, B. G., Exotic Disease in Practice. London, Heinemann, 1965. 2 British Medical fournal, 1971, 2, 1.

3 Public Health Laboratory Service, 1971 Year Book including Annual Report for 1970. London, 1971.

4 Dorolle, P., British Medical fournal, 1968, 4, 789. World Health Org

- Department of Health and Social Security, Communicable Diseases Contracted Outside Great Britain, 1968 (new edition in press).

7 Ross Institute of Tropical Hygiene, Preservation of Personal Health in Warm Climates, 7th edn. London, 1971 .

8 Shute, P. G., and Maryon, M., British Medical fournal, 1969, 2, 781.

9 Bruce-Chwatt, L. J., Draper, C. C., and Peters, W., British Medical Fournal, 1971, 2, 91 .

10 Ross Institute Information and Advisory Service, Antimalarial Drugs. (Bulletin No. 2) London, 1972.

11 Peters, W. Chemotherapy and Drug Resistance in Malaria. New York, Academic Press, 1970.

\section{Mercury in the Environment}

In the past few years several careful studies in different parts of the world have drawn attention to the exposure of the human population to mercury in its different chemical forms. They were briefly reviewed in these columns ${ }^{1}$ after the discovery that some popular edible fish might contain up to 0.5 p.p.m. methyl mercury which they had picked up from their natural environment. Could fish containing such amounts of methyl mercury present a health hazard to their human consumer? The question was raised by the discovery that in some situations waste mercury, deposited in what was believed to be the biologically insignificant form of the insoluble sulphide, could be converted to water-soluble toxic methyl mercury derivatives by micro-organisms. It is not therefore surprising in view of other public statements ${ }^{2}$ and reviews ${ }^{3}$ that the Expert Committee on Food Additives convened by the World Health Organization and the Food and Agriculture Organization should have set itself the task of proposing an acceptable daily intake of the three toxic chemicals lead, cadmium, and mercury, and will issue a report.

Mercury in its various chemical forms presents different hazards to man. It is generally accepted that the lower alkyl mercury derivatives-methyl or ethyl mercury salts-have a unique destructive effect on the nervous system of higher animals and man. This has been found because people have been accidentally or occupationally exposed to concentrations of these organo-mercury compounds generated directly by man's activities. There is no indication that mercury of natural origin and dispersion is converted to methyl mercury in dangerous concentrations, but mercury released by human activities in different forms can be so converted in amounts that have killed or crippled thousands of people. It is right that the hazards presented by mercury in our human environment should arouse concern, but equally they must be seen in perspective. While the deaths of 2,000 people in Iran recently from the effects of an earthquake were given publicity, little attended the deaths of several hundred and the crippling of many thousands of Iraqis to which reference was briefly made in our columns ${ }^{4}$ in an appeal for help. The deaths and disability affecting the Iraqis were due to a toxic substance made by man and introduced into that country as a seed dressing aimed at improving th eyield from wheat or barley. Unfortunately, the seed grain was dressed with a mercurial compound known to produce irreversible injury in man. It was distributed after the sowing season ${ }^{5}$ and so was eaten by a people used to eating their seed grain. 67 The current concern with environmental hazards is finding expression at a U.N. conference in Stockholm. But will anything be done to control the manufacture of certain fungicides and insecticides that have already killed and crippled thousands of people?

The human wreckage from the distribution of methyl mercury is widespread in parts of Asia. The International Red Cross did a fine job in organizing the rehabilitation of 10,000 people paralysed by triorthocresyl phosphate sold as edible cooking oil in Morocco in 1959,8 but the devastation in Iraq is probably less amenable to therapy and rehabilitation. There is a danger that hypothetical hazards will attract study while little is done to prevent real hazards, for it is easier to form pious resolutions than to stop people doing dangerous things. But the manufacturers and distributors of substances known to be dangerous can be identified 